REsumo

Este trabalho aborda o fenômeno da desvalorização do conbecimento na contemporaneidade. Sua bipótese central é a de que as últimas décadas foram decisivas para que o conbecimento perdesse na sociedade sen valor de uso, marca característica de uma tradição milenar iniciada com o mito de Adão e Eva e estendida até o advento do marxismo, para o qual o conbecimento tinha valor emancipatório, para ceder lugar ao valor de troca, que torna o interesse pelo conhecimento apenas instrumental.

Descritores: declinio; saber; conbecimento; psicanálise; despsicologização.

\section{O CONHECIMENTO E O DISCURSO DO CAPITALISTA: A DESPSICOLOGIZAÇÃO DO COTIDIANO SOCIAL}

\author{
Rinaldo Voltolini
}

(P) na prova? Professor! Para que vai me servir isto que estamos aprendendo?

Todos já terão feito a prova. A banalidade dessa situação, em contraste com a profundidade dos problemas que ela anuncia, tem despertado o interesse de muitos que tentam reunir esforços para retomar um sentido para o conhecimento.

O conjunto desses esforços, entretanto, é imperioso constatar, mostraram-se em seu conjunto impotentes para resolver o problema. A falta de sentido do conhecimento segue sendo uma das principais mazelas com que a escola contemporânea tem que conviver. Ela não se restringe ao universo dos alunos, mas atinge também os professores que têm, cada vez mais, dificuldade de justificar e defender, para 


\section{Artigo}

além da sua própria valorização particular, o valor de certos conteúdos.

O debate constante sobre a valoração dos conteúdos a serem ministrados pelas disciplinas, ou ainda sobre a própria pertinência ou não da existência de determinadas disciplinas anima tensões acirradas, nas quais sempre se tende ao corporativismo, acionado por todos os lados envolvidos, o que demonstra que em todos os níveis se cedeu à dinâmica do mercado, do valor de troca.

Nesses debates oscila-se entre diversas posições. Num extremo encontramos a defesa de um ponto de vista mais pragmático, que soube ouvir e representar as vozes do mercado demandando a veiculação de saberes úteis à maquinaria que move os interesses financeiros. Em outro extremo, a defesa de uma certa universalização mínima dos conteúdos necessários a uma formação cidadã e comprometida com os problemas gerais da sociedade.

Os pedagogos tentam equacionar o problema e tomar providências para fazer a escola reagir e retomar o sentido do conhecimento.

Normalmente consolidam a hipótese de que a falta de interesse do aluno pelo conhecimento é culpa dos métodos escolares - afinal todas as crianças pequenas, comentam os educadores, assim que entram na escola demonstram um vivo interesse por aprender que vai se diluindo aos poucos para se transformar numa apatia incontornável. 
As acusações ora tendem para a inaptidão da escola em apresentar os conteúdos de modo a despertar o apetite por eles, ora para a não justificativa adequada desses conteúdos de maneira a fazer o aluno entender sua não arbitrariedade.

E o problema ainda se avoluma quando se atesta que esse desinteresse e a falta de sentido dos saberes contribui para uma deslegitimação da instituição escolar, que vai sendo tomada como arbitrária e autoritária, pois se impõe aos indivíduos sem razão de ser.

Uma certa especularidade se estabelece: se a escola não tem sobre mim outro interesse que não o de exercer um poder de controle, eu não terei por ela nenhum outro interesse senão o de exercer um poder de controle. Daí as estratégias do aluno, tantas vezes lamentada pelos professores, desde a cola até o uso perverso do "a escola não pode me reprovar", que também não fazem senão denunciar a falta de sentido da qual padece a escola.

As tentativas da pedagogia para resolver o problema são impotentes porque o problema não é pedagógico.

A verdade é que nós não estamos diante de um problema técnico que poderia ser regulado pelos meios escolares. A pedagogia se choca neste ponto, gostaria de mostrar, com um fenômeno que a ultrapassa sobremaneira. Um fenômeno civilizatório e antropológico fundamental, que não pode ser verdadeiramente abordado sem sair do quadro das instituições educativas. O que se encontra aqui, recolocado em questão, atinge, com o estatuto do saber, as condições mesmas de reprodução de nossas sociedades. (Blais, Gauchet \& Ottavid, 2008, p. 66, tradução nossa)

Talvez pudéssemos, nesse ponto, dizer sobre a pedagogia o mesmo que Foucault (1984) disse sobre a Psicologia: que ela não poderia compreender a educação na medida em que a apreende desde sua institucionalização. A pedagogia não pode compreender a educação enquanto esta for abordada no quadro estrito de sua institucionalização.

A tese de que as crianças seriam desencaminhadas de seu interesse pelo conhecimento pela escola, prova uma rasa identificação com a tese rousseauniana da corrupção do indivíduo pela sociedade, nega que a criança não é uma natureza transformada pela sociedade. A constituição do sujeito não se dá fora das regras em curso numa dada sociedade, num dado momento de sua evolução, de modo que se as crianças estão se desinteressando pelo conhecimento em um determinado momento não seria porque a sociedade, globalmente, realiza o mesmo processo? 


\section{Artigo}

\section{O declínio dos saberes}

Durante séculos o conhecimento ocupou um lugar de extremo destaque na humanidade. Já num mito bíblico, o de Adão e Eva, a sede de conhecimento valia o preço da perda do paraíso. A perfeição do paraíso não era completa, algo faltava, e a curiosidade em descobrir o que faltava era superior aos bens ofertados.

Com o advento das luzes essa sede de conhecimento ganhou um novo impulso. Conhecer, agora passava a significar o principal instrumento, a via régia da emancipação. Tomar o destino nas mãos e não mais relegálo integralmente à vontade divina, nem mais se deixar absorver pelas explicações obscurantistas contidas na palavra dita revelada por Deus, representava o mote de toda uma época que depositou no conhecimento todas as esperanças de uma guinada da humanidade.

A ciência moderna buscava a verdade nos fatos, não mais na palavra de Deus, e os primeiros descobridores e inventores, como Galileu, por exemplo, tornaram-se grandes celebridades, vencido, é claro, o primeiro tempo de ostracismo e de perseguição, deflagrada graças ao impacto no status-quo representado por suas formulações.

Durante séculos também, o corpo foi entendido como o lugar do sofrimento, precariedade terrena, imperfeição e infelicidade; o espírito, a 
possibilidade de elevação da miséria, do culto ao que há de mais divino em nós. Era a maneira de ultrapassar os limites da morte e do cultivo de uma eternidade, não necessariamente aquela do reino divino, mas, sobretudo, daquela que restaria, por meio da história, entre os homens.

Nos dias que são os nossos o conhecimento não goza mais do mesmo status. Adão e Eva seriam figuras altamente improváveis; quem trocaria o paraíso pelo conhecimento? $\mathrm{Ou}$ ainda, quem acredita que o acesso ao paraíso depende do processo conhecimento? Muito mais provavelmente, em sintonia com as coordenadas da contemporaneidade, ouve-se, sobre o acesso ao paraíso, que ele depende do produto diploma.

Mesmo a convicção no poder das Luzes e do esclarecimento perdeu fôlego e a promessa sustentada tacitamente de que o conhecimento científico viria oferecer um conforto equivalente ao que a palavra divina tinha podido oferecer por séculos, visivelmente não se sustentou, como mostram, entre outras coisas, a recrudescência do empuxo à religião e o receio sempre à espreita de que com os próprios objetos criados pela ciência venhamos a dar fim na humanidade.

A própria ciência perdeu o atrativo enquanto saber emancipatório para tornar-se, sobretudo, um meio de concretizar objetos para o consumo. Ela que já tinha sido atraente por suas descobertas revolucionárias, por sua capacidade de girar o mundo, re- flete mais, hoje em dia, a imagem de um saber do tipo "super interessante". Dela não se espera mais a revolução, mas o conforto.

Os cientistas deixaram de ser heróis para se tornarem anônimos, sem brilho e por trás dos objetos inventados. Quem conhece o nome ou a história do inventor do celular? "Cientistas" descobriram medicamentos que controlam a carga viral do HIV!

O espírito, lugar da esperança de elevação da miséria mundana, é cada vez mais identificado como parte dessa mesma miséria, como mais um órgão do organismo. Tudo no psiquismo pode ser reduzido ao substrato orgânico e a alma talvez não seja mais do que algumas secreções químicas, reza uma das principais crenças contemporâneas. Desse modo, o corpo é promovido ao primeiro plano.

Não nos deteremos na teia complexa de fatores que engendraram esse giro na história, remetendo o leitor interessado à gama significativa de trabalhos de sociologia e história que atestam e desenvolvem esta complexidade.

De nossa parte e para nossos fins interessa destacar e desenvolver o que desse giro podemos reter para nos ajudar a compreender a constatação que nos convoca: o declínio do sentido do conhecimento e seu impacto na realidade educativa.

Nossa hipótese, engendrada desde a psicanálise, é de que esse declínio passa substancialmente por uma 


\section{Artigo}

operação, escrita por Lacan (1972) na fórmula do discurso do capitalista que designou um modo particular, inédito na história até então, de relação do sujeito com o objeto. Modo este em que o objeto, agora coisificado por sua produção em série, empirizado pelo discurso científico, desconectado de seu fundo de ausência, tal como destacou a psicanálise com os conceitos de pulsão e de desejo, vem determinar, artificialmente, um "sujeito em série", votado para o consumo.

A hiperinflação do objeto, empreendida pelo capitalismo, visa estabelecer entre o sujeito e o objeto uma complementaridade sem arestas, o objeto sob medida na linguagem mercadológica, a existência da relação sexual, nos termos lacanianos, o paraíso nos termos bíblicos.

A não convivência pacífica, sem conflitos, entre o paraíso e o conhecimento, cerne do drama adâmico, foi percebida e teorizada por Freud, que reconheceu nessa tensão o motor do conhecimento.

Lembremos que, para Freud, o sentido do conhecimento se engendra fundamentalmente nos entraves do processo pulsional. Seja quando se trata do bebê que, impossibilitado de satisfazer-se plenamente com a alucinação do seio, primeiro procedimento com o qual tenta dar conta do aumento de tensão no aparelho psíquico, inicia sua pesquisa da realidade, seja no jovenzinho que, preocupado com os riscos da chegada de um rival inicia sua teorização sobre a 
relação sexual, é sempre a partir de uma falta, siderante e sinérgica para o sujeito, que a tentativa de conhecer se engendra.

É a renúncia ao imediatismo do prazer que permite acessar o conhecimento.

No mesmo plano, ainda que formulado em termos e contextos diferentes, o mesmo fenômeno pode ser reconhecido na teorização marxista, através do conceito de alienação, que de todo modo também demarca que uma operação sobre o conhecimento, o desconhecimento no caso, é necessária para que o capitalismo possa vender sua promessa de paraíso. Em Marx conhecer, desalienar-se, também faz cair o objeto de seu lugar de Zenith.

Nossa educação atual tem que se dar num contexto em que o objeto foi promovido ao lugar do Zenith e que, como tal, tem problemas para sustentar o sentido do conhecimento. Qual seria o atrativo do conhecer se o paraíso dos objetos se oferece a mim sem limites. Bastaria uma cota de sacrifício, o trabalho de doar uma costela, para que se apresente à minha frente aquela que completará a minha falta.

Mas os conhecimentos continuam a ser veiculados, nos objetariam, pela escola ou por outros agentes educativos, até mesmo por sua disponibilidade nas redes da Internet, etc. É verdade, mas sua veiculação não depende mais agora de sua vinculação às teias do processo pulsional e desejante. Bem entendido, esta ocorrerá inevitavelmente, mas sua ocorrência não tem valor no quadro geral das forças que movem o sistema.

Os vários conhecimentos ganham valor utilitário, como indicado pelas perguntas comuns dos alunos, sublinhadas por nós no primeiro parágrafo desse texto.

Se a oferta de conhecimentos deixar de se conectar com o campo desejante, esteio que sempre serviu de lastro para o sentido, para desempenhar um papel acumulador (sublinhemos aqui a relação direta deste termo com a lógica capitalista), com valor dentro do jogo de trocas mais do que de uso, como tantas vezes já se fez observar no interior da própria crítica pedagógica, ela inevitavelmente decairá em perda de sentido.

Até aqui nos deparamos com uma verdade banal, reiterada pelo discurso pedagógico e suas tentativas de retomar o sentido do conhecimento para o indivíduo.

O ponto a avançar e que muda o epicentro da questão é que não se trata de pensar em significação individual do conhecimento, 
marca que demonstra a adequação do discurso pedagógico à lógica capitalista, mas em significação coletiva.

O problema do declínio do sentido do conhecimento não se resolve com tentativas de dar sentido individual ao conhecimento porque o sentido é algo que não pode ser encontrado fora da referência a um outro, fora, portanto, de uma tradição.

Toda a psicologia que influenciou o pensamento pedagógico atual é repleta desse equívoco. Fala-se em motivação intrínseca ou extrínseca, ou que o próprio aprender é motivante, etc., tudo para marcar que o sentido do conhecer se daria no âmbito individual.

Não é de estranhar, entretanto, que a psicologia tenha sido capturada por esta lógica, quando conhecemos as condições de seu nascimento científico, bastante comprometido, como tantas vezes apontado (Patto, 1987) com a tecnocracia capitalista.

Mas é preciso relembrar a função necessariamente coletiva e coletivizante do conhecimento.

\section{Individualismo e a queda da tradição}

A presença hegemônica da psicologia nas discussões pedagógicas, como bem demonstrou Lajonquière (1999) tem um fundamento político: a consolidação do individualismo, ideologia necessária ao pleno desen- volvimento do empreendimento capitalista.

Como demonstrou Patto (1987), por trás da aparente diversidade da psicologia, flagrante quando nos atemos ao registro epistemológico, existe uma unidade ideológica, aquela que garante que há um indivíduo, descrito em seu viés abstrato e fora das relações reais que concretizam sua existência.

Desse modo o ser do indivíduo poderia ser compreendido fora de sua existência, gerando o indivíduo isolado. Mesmo suas relações com os outros passam a ser concebidas como produto de sua potencialidade psicológica: a sociabilidade.

Numa referência psicanalítica diríamos que não haveria o Outro, só os outros.Mas é no Outro e não nos outros, nem nos objetos, que o sentido se estabelece.

A criança só interroga um objeto qualquer porque ele lhe é apresentado por alguém que sustenta sua significação num além de si mesmo. Fora desse enlaçamento os objetos permanecem carentes de qualquer sentido. É como um dom que o objeto desperta interesse, ou mesmo seu contrário, o desinteresse.

Um texto, por exemplo, cujo conteúdo despertaria em outras condições $\mathrm{o}$ interesse de um adolescente, dada a sua relação com seu repertório desejante, torna-se insípido simplesmente porque sua leitura foi imposta.

Não há conhecimento cujo sentido não se assente no laço que o liga 
a uma turba discursiva na qual todos pegamos carona.

A tradição é um outro nome para o Outro; seu próprio sentido etimológico o indica: tra' dicção, ou seja, algo que se passa por meio da dicção. Trata-se fundamentalmente de um lugar linguageiro.

Se quisermos sustentar que o sentido do conhecimento está no objeto ou no indivíduo, como parecemos crer em nossa época, este sentido certamente se esvaziará.

Resulta interessante observar como o behaviorismo, teoria mais representativa do individualismo e que consagra a unidade ideológica da psicologia a que nos referíamos acima, constrói seu aparato conceitual e, em particular, qual o sentido e o valor que o conhecimento vão ter neste sistema teórico.

A cena sempre aludida de sua origem, o cão de Pavlov ou a caixa de Skinner, são exemplos interessantes para discutir a queda da tradição e do valor do conhecimento, mas também, como veremos, a despsicologização do homem.

A Naturalização do humano é o projeto promovido pelo behaviorismo que, assim fazendo, despsicologiza o homem.

A emergência de uma teoria como a behaviorista, comprometida com a adesão ao ideal e aos métodos das "Ciências Naturais" no estudo do homem já foi inúmeras vezes apontada como a operação que garantiria a cientificidade da Psicologia, não por

114 Estilos da Clínica, 2012, 17(1), 106-121 
sua consistência epistemológica, que permanece sendo uma questão problemática, mas, por seus serviços prestados à Tecnocracia.

O mérito de tal observação está principalmente em seu poder de deslocar a discussão de um nível meramente epistemológico onde o behaviorismo pareceria poder sustentar suas premissas, para o nível ideológico, onde podemos apreendê-lo em suas conexões com a legitimação científica de uma nova discursividade social (a Capitalista) para a qual ele viria prestar seus serviços.

A lamentável verdade, no que concerne ao behaviorismo e a validade de suas 'leis', é que quanto mais pessoas há, mais elas têm a tendência de 'bem se conduzir' e de não suportar o não-conformismo. $\mathrm{Na}$ estatística, o fato é posto em evidência pelo nivelamento das flutuações.... A uniformidade estatística não é de modo algum um ideal científico inofensivo. (Arendt citada por Gori \& Del Volgo, 2005, p. 211)

O que há de desagradável nas modernas teorias do comportamento, não é que elas sejam falsas, mas que elas podem se tornar verdadeiras, é que elas são, de fato, a melhor demonstração possível em conceitos de certas tendências evidentes da sociedade moderna. (p. 214)

A imagem já célebre do rato preso numa caixa que o limita, "privado em suas necessidades vitais", forçado a obedecer ao comando do experimentador que deseja que ele "aprenda" certos truques que lhe garantirão a vida, tem mesmo um valor paradigmático, cujo significado seria importante analisar, não naquilo que isso mostraria d"A" aprendizagem (o maiúsculo servindo aqui para marcar a ambição de encontrar uma lei geral do funcionamento humano), mas naquilo que isto guarda de relação com as vicissitudes da Educação atual.

O primeiro ponto a observar é o da pretensão de equivalência entre o comportamento animal e o humano que tal orientação de pesquisa está inclinada a admitir. De fato, a perspectiva de tratar o homem a partir das coordenadas das Ciências Naturais não podia se dar sem perseguir as leis da "Natureza Humana".

Toda a afirmação sobre o homem como um ser "desnaturado", concepção clássica que continua a sustentar outra orientação de pesquisa do homem, não pode senão ser tratada dentro de tal perspectiva como uma posição preconceituosa, que acarretaria atrasos ao estudo do comportamento humano.

Não que a própria teoria behaviorista não faça, ela mesma, uma certa experiência dessa desnaturação do homem, fato que ela está 
inclinada a negar (no sentido freudiano do termo, ou seja, para esconder um conflito, para se defender, se proteger de uma ameaça a si mesma), pois tudo nela a prepara para não acolher em seu domínio conceitual tal consideração.

Refiro-me ao que esconde uma certa ambigüidade presente no conceito de "condicionamento", tão fundamental para a teoria behaviorista. Nesse conceito fica reconhecido que o comportamento depende de certas "condições", sem as quais não poderia manter-se, sem que, contudo, se chegue a reconhecer o quanto a suposta Natureza humana é frágil dada a imensa possibilidade de alteração que a própria teoria behaviorista se empenha em defender. Ou ainda, sem chegar a constatar que a noção de Natureza humana é ela mesma uma construção conceitual que dependeu também de certas "condições" históricas para aparecer. Na verdade sem poder reconhecer que a Natureza humana é mesmo, como diria Arendt (citada por Gori \& Del Volgo, 2005), junto com tantos outros a "Condição" Humana.

Resulta interessante observar como todo este empreendimento naturalista em Psicologia parece ter se iniciado (pelo menos todos o narram como um mito original), "paradoxalmente", com a impressionante formulação de Pavlov ao conseguir demonstrar que era possível alterar em seu cachorro-cobaia uma resposta instintiva em prol de outra aprendida. Enfim, seu cachorro já podia sali- var diante do simples som de uma campainha ao invés de só emitir esta resposta face à visão de seu alimento, tal como a Natureza lhe havia dotado. Ou seja, que era possível "desnaturar" seu cachorro. Lacan (19671968) observou esta peculiaridade do empreendimento behaviorista.

Na psicanálise essa aproximação entre o homem e o animal é absolutamente impensável. O empalidecimento da noção de instinto em prol da noção de pulsão, a valorização de temas como os sonhos, os chistes, a cultura, os esquecimentos, tão exclusivos do humano, são marcas disso. Todo o empreendimento teórico de Freud pode ser compreendido como uma insistência em demonstrar e extrair as conseqüências do fato de nossa diferença em relação aos animais, sem precisar, contudo, aderir a nenhuma tese do "privilégio na Criação".

Desde Freud a expressão "virar gente”, consagrada pelo senso-comum, ganhou seu mais expressivo sentido: o de que ser homem não é um atributo natural, inato, ainda que o seja sua potencialidade, mas, antes, uma construção que é sempre tributária de certas "condições". E mais ainda, acrescentaríamos seguindo a perspectiva freudiana, que esta construção caminha na direção de uma desnaturação do homem, de um afastamento do pouco que a Natureza nos dotou para a sobrevida.

Para a Psicanálise seria justamente a precariedade instintiva inicial, a vacância deixada pelo "saber" 


\section{Artigo}

instintivo na determinação do comportamento humano que, abrindo espaço à instalação do pulsional, permite a constituição do humano segundo regras nas quais a Natureza conta pouco.

Particularmente, diríamos que é na fragilidade do saber instintivo, que não reclama nenhum sentido, que o saber tramado nas pulsões ganhará terreno

Lacan explicitaria ainda melhor, com conseqüências sobre a questão do conhecimento, essa diferença fundamental entre o homem e os animais em seu estudo sobre o estádio do espelho (Lacan, 1966) por meio da comparação entre o que se passa com o manejo da imagem em uns e em outros.

No homem, seu corpo, a partir de um momento inaugural e daí para sempre, restaria comprometido com a imagem unificada dele, capturada no espelhamento que o outro que se ocupa do infans lhe possibilita quando simplesmente olha para ele como um sujeito. Fascinado com a própria imagem retornada desse espelho o humano não poderá jamais, ao longo de toda sua vida, deixar de apaixonar-se por ela, a ponto de que em todas as suas futuras relações estará, feito Narciso,"condenado" a vê-la aparecer como uma sombra que media a relação com o outro.

É por isso que a criança, ainda bem imatura, responde com um sorriso jubiloso ao reflexo de sua própria imagem no espelho, experiência 
sem equivalentes no mundo animal. Ainda que em certas experiências alguns animais tenham sido levados a identificar sua própria imagem no espelho e não mais reagir a ela como se se tratasse de um outro, nunca se verificou a presença do júbilo nesta resposta.

O corpo do homem estará marcado para sempre, a partir daî por um certo "em relação a", "assim me vejo e te vejo segundo a forma pela qual fui visto".

O conhecimento também aparece nesse texto de Lacan que aî irá adjetivá-lo de paranoico, para marcar o caráter decisivamente relacional de seu engendramento.

Dizer que o conhecimento é paranoico, fórmula que não vale apenas para os paranoicos, significa, entre outras coisas, que não podemos acessar nenhum objeto sem ver nele nossa própria imagem, que por sua vez sempre se instaura na relação especular.

Temos, então, uma diferença crucial entre a Psicanálise e o Behaviorismo na medida que para a primeira, a comparação com o animal sempre mostrará a diferença, enquanto para o segundo a mesma comparação buscará as semelhanças.

Mas o rato dos experimentos de Skinner só aprende porque algo de sua necessidade está em jogo, ou seja, o conhecimento daí derivado será intrinsecamente "utilitário".

Pressionado pelas estratégias do experimentador, ele adquire os recursos que lhe servem para matar a sede, ou para escapar do choque.

A ideia de aquisição de conhecimento que aí se estabelece nasce solidária a um utilitarismo cujas bases seriam controláveis por um planejamento científico.

Mas é também interessante observar, como o protótipo experimental do rato revela, que o conteúdo ensinado, nessa perspectiva, é "inútil". De fato, qual a relevância de ensinar um rato a manipular uma manivela? Mesmo que os experimentos se complexifiquem daí em diante, na direção de aquisições mais significativas, não é irrelevante que o mito original dessa teoria esteja comprometido com o utilitário e com o sem sentido.

Essa perspectiva não demonstraria, à revelia de si mesma, como convém a tudo que é ideológico uma vez que não depende da consciência para se disseminar, que o conteúdo ensinado "não precisa ter sentido"? O que importa são as habilidades a serem atingidas.

Ainda que de maneira provocativa, mas para acentuar a dimensão política do que está em jogo, poderíamos dizer que aprender a 


\section{Artigo}

manipular a manivela não serve para o rato conviver com outros ratos, mas tão somente para resolver a "sua" necessidade, o que demonstra o compromisso desta perspectiva com o individualismo enquanto política.

Se o essencial da teoria behaviorista, como indicamos acima por meio de Arendt, reside no fato de que seus postulados refletem a ideologia dominante da sociedade contemporânea, temos aqui o corolário de como nossa sociedade encara o conhecimento: utilitário, sem sentido relacional, atrelado à necessidade e não ao desejo, individualista.

Nesses termos, sob o ápice da "biologização" do homem e sua conseqüente despsicologização, operada pelo paradigma S-R que exclui toda referência a uma mediação simbólica entre o estímulo e a resposta, encontramos uma alteração fundamental do processo de conhecimento. Ele não precisaria, segundo essa perspectiva, passar pelas redes desejantes, nem encontrar seu sentido no campo do Outro, mas apenas visar o domínio de um objeto cujas coordenadas, inclusive, estariam sob o comando dos experimentadores, de quem, é óbvio, só podemos esperar que tenham sempre as melhores intenções.

A constante promoção do "bios" como explicação derradeira para as questões humanas é flagrante em nossos tempos. Ela aparece na estandartização da genética como explicação para todos males que afligem o homem, e aparece também na promo- 
ção do valor da vida como bem mais fundamental da sociedade, etc.

Sua denúncia já foi feita pela pena focaultiana através do termo "bio-poder", mas talvez caiba à psicanálise esclarecer a relação intrínseca que esta biologização guarda com a despsicologização do homem, que segue sendo um tema importante para futuros estudos.

É ela que possibilita que o homem e animal sejam considerados comparáveis e aproximados em suas semelhanças.

Quanto mais nossa sociedade e, por tabela, nossas escolas, funcionarem como caixas skinerianas, menos sentido terá o conhecimento e nenhuma medida pedagógica poderá ter sobre isto uma ação que não seja paliativa.

THE KNOWLEDGE AND THE DISCOURSE OF OF THE CAPITALIST: THE DEPSYCHOLOGIZATION OF THE DAILY SOCIAL LIFE

\section{Abstract}

This paper deals with the phenomenon of the devaluation of knowledge in contemporaneity. Its central hypothesis is that the last decades have been decisive to make knowledge lose its use value in society, a characteristic mark of a millennial tradition initiated with the myth of Adam and Eve and extended up to the advent of Marxism, for which the knowledge had an emancipatory value, to give place to exchange value that makes the interest for knowledge only instrumental.

Index terms: decline; unconscious knowledge; knowledge; psychoanalysis; de-psychologization. 


\section{Artigo}

EL CONOCIMIENTO Y EL DISCURSO DEL CAPITALISTA: LA DESPSICOLOGIZACIÓN DEL COTIDIANO SOCIAL

\section{RESUMEN}

El presente trabajo aborda el fenómeno de la depreciación del conocimiento en la sociedad contemporánea. Su hipótesis central es que las últimas décadas han sido cruciales para que el conocimiento pierda su valor de uso en la sociedad, lo cual fue una marca característica de la antigua tradición que comenzó con el mito de Adán y Eva. Esta concepción se extendió hasta el advenimiento del marxismo, para el cual el conocimiento tenía un valor emancipador, pero que cedió lugar al valor de trueque, lo que tornó el interés por el conocimiento en sólo instrumental.

Palabras clave: destitución; saber; conocimiento; psicoanálisis; despsicologización.

\section{REFEREANCIAS}

Blais, M. C., Gauchet, M. \& Ottavid, D. (2008). Conditions de l'éducation. Paris: Stock.

Foucault, M. (1984). Doença mental e psicologia. Rio de Janeiro: Tempo Universitário.

Freud, S. (1996). A organização genital infantil: uma interpolação na teoria da sexualidade. In S. Freud, Obras completas (J. Salomão trad., Vol. 19, pp. 153163). Rio de Janeiro: Imago. (Trabalho original publicado em 1923)

Gori R. \& Del Volgo M. J. (2005). La santé totalitaire: essai sur la médicalisation de l'existence. Paris: Denoël.

Lacan, J. (1972). Du discours psychanalytique. In J. Lacan, Lacan en Italie (pp. 3254). Paris: Seuil.

Lacan, J. (1967-1968). O ato psicanalitico. (inédito)

Lacan, J. (1998). O estádio do espelho como formador da função do eu. In J. Lacan, Escritos (V. Ribeiro trad., pp. 96-103). Rio de Janeiro: Jorge Zahar. (Trabalho original publicado em 1949)

Lajonquière, L. de. (1999). Infância e ilusão (psico)pedagógica: escritos de psicanálise e educação. Petrópolis, RJ: Vozes.

Patto, M. H. S. (1987). Psicologia e ideologia: uma introdução à psicologia escolar. São Paulo: T. A. Queiroz. 